\title{
The effect of egg powder inclusion in the pre-starter diet on the immune response of male broiler chickens
}

\author{
Ladan Esmailzadeh', Mahmud Shivazad', Ali Asghar Sadeghi' and Mohamadamir \\ Karimi-Torshizi ${ }^{2}$
}

'Department of Animal Science, Science and Research Branch, Islamic Azad University, Tehran, Iran, ${ }^{2}$ Department of Poultry Science, Faculty of Agriculture, Tarbiat Modares University, Tehran, Iran

\begin{abstract}
A completely randomised design was performed to evaluate the effect of inclusion of egg powder in the pre-started diet (1-7 day age) on the immune response of male broiler chickens. Experimental pre-starter diets formulated to have $0,20,40$ or $60 \mathrm{~g} / \mathrm{kg}$ egg powder. The relative weight of lymphoid organs (spleen and bursa) was reduced, in days 7 and 42 of age, by graded inclusion of egg powder in the pre-starter period $(P \leq 0.05)$. The highest antibody titre against Newcastle disease virus (NDV) and Infectious bronchitis virus (IBV) in days 7 and 42 of age was for chickens fed the diet containing $60 \mathrm{~g} / \mathrm{kg}$ egg powder in the pre-starter diet $(P \leq 0.05)$. At day 7 of age, birds fed the diet containing egg powder had a higher antibody titre against Infectious bursal disease virus (IB) compared to the control group $(P \leq 0.05)$, but at day 42 of age, there was no significant difference between the treatments $(P>0.05)$. There was no difference $(P>0.05)$ among the treatments for the titre against sheep red blood cells and immune response against dinitrochlorobenzene. It was concluded that the inclusion of egg powder to the pre-starter diet could significantly enhance the immune response of the male broiler chickens.
\end{abstract}

Keywords: egg powder; pre-starter; immune response; antibody titre; broiler

Abbreviations: DNCB: 2,4 dinitro-1-chlorobenzene; IB: Infectious bursal disease virus; IBV: Infectious bronchitis virus; NDV: Newcastle disease virus; PHA-P: phytohaemagglutinin-P; SRBC: sheep red blood cell

Archiv Tierzucht 56 (2013) 51, 527-535

doi: 10.7482/0003-9438-56-051

Corresponding author:

Ali Asghar Sadeghi; email: a.sadeghi@srbiau.ac.ir

Department of Animal Science, Science and Research Branch, Islamic Azad University, Poonak, Hesarak, Tehran, 1477893855, Iran

() 2013 by the authors; licensee Leibniz Institute for Farm Animal Biology (FBN), Dummerstorf, Germany. This is an Open Access article distributed under the terms and conditions of the Creative Commons Attribution 3.0 License (http://creativecommons.org/licenses/by/3.0/).
Received: 7 January 2013

Accepted: 19 February 2013

Online: 26 April 2013 


\section{Introduction}

A newly hatched chicken has an incapable digestive system to process conventional feed ingredients. This incapability comes from both morphologic and also enzymatic aspects. In this period, chickens have high levels of nutritional requirements to support growth and development of the gastrointestinal system and also the immune system to warranty the health and ultimate production of the bird (Noy \& Sklan 2001).

An egg during the incubation period fulfil all nutritional requirements of embryo and there is a very strong relation between egg weight and subsequent hatched chicken weight. The most important point after immediate access to feed is the nutritional value of feed ingredients for chickens in the early time after hatch. The importance of early feeding of newly hatched chicks on their performance and health was demonstrated by several studies (Jin et al. 1998, Noy \& Sklan 1999, Juul-Madsen et al. 2004). Most of the feed ingredients like grains and plant origin proteins which used in diet of chickens had a low utilisation for chickens at early times after hatching. The main reason of this poor ability is the immature gastrointestinal tract of chickens (Juul-Madsen et al. 2004). In addition to that disability, new hatched chickens have a high level of nutrient requirement because of their accelerated growth of the gastrointestinal system and other organs related to nutrition and immunity. This high level of growth in the gastrointestinal system needs more digestible feed ingredients to support consequent growth in all parts of the chicken body like in muscles, skeleton and immune system.

Also there are important interactions and antagonisms between nutrition and immunity that affect the productivity of poultry. Sever deficiency of most nutrients impairs the immune response and increase susceptibility of birds to infectious diseases. Severe nutrient deficiencies are particularly deleterious to the immune system when they occur early in life during the development of the primary lymphoid organs and the maturation of immune system (Kirk 1997).

Thus, these facts oblige nutritionists to pay special attention to nutritional requirements of chickens in early time after hatching. One of the best choices to support nutritional requirements of newly hatched chickens is the application of pre-starter diets. These prestarter diets must provide highly digestible ingredients for the young chickens. Nowadays a lot of researches have been conducted to evaluate new alternatives for feeding young chicks. Because before hatching all nutritional requirements of the embryo come from egg reserves, eggs and egg by-products could be used as a good choice to feed newly hatched chickens. Egg by-products include outcomes from breaking facilities and unsellable eggs. Sparks (2006) reported that these by-products are rich in fat, maternal antibodies, protein and bioactive nutrients. Other beneficial effects of consuming egg by-product are showed in studies conducted by El-Deek \& Al-Harthi (2009) and El-Deek et al. (2011). They concluded that dried egg powder may be used as an alternative to antibiotics due to its high content of antimicrobial proteins and eggs antibodies and it could be fed to large flocks without negative effects on performance of chickens. In the literature, there was no information regarding the antibody titres of broiler chicks fed egg powder during the pre-starter period. Therefore, the objective of this study was to evaluate egg powder as an alternative in the prestarter diet of broiler chickens and its influence on the immune response of chickens. 


\section{Material and methods}

Birds, diets and experimental design

The sample of egg powder was obtained from the Golpoodr Company (Gorgan, Iran). Egg powder had been prepared from both egg white and egg yolk which was spray-dried at $55^{\circ} \mathrm{C}$. Chemical composition (crude protein, ether extract, crude fibre, Phosphorous and Calcium) of egg powder and other feed ingredients which were used in this experiment were analysed using AOAC (1990). The amino acid content of egg powder was analysed using near infrared reflectance spectroscopy method (FieldSpec Pro, Analytical Spectral Devices, Boulder, CO, USA). Nutrient contents of egg powder are shown in Table 1. The experimental period was divided in four phases: pre-starter (from hatch to day 7), starter (from day 8 to day 10), grower (from day 11 to day 24) and finisher period (from day 25 to day 42). Experimental treatments were four levels of egg powder inclusion in the pre-starter diet of male broiler chickens. Egg powder levels in the pre-starter diet of birds were $0,20,40$ or $60 \mathrm{~g} / \mathrm{kg}$ of the diet. In the starter period (from day 8 to day 10 ) all birds consumed the diet which the control group consumed in the pre-starter period. Experimental diets were formulated according to Ross 308 management manual and all of them had equal amino acids and metabolisable energy (Table 2). Each treatment had four replicates with 20 male broiler chickens. Feed and water were available ad libitum all over the experiment. Birds were housed over wired floor pens under ambient temperature and continuous light was provided.

Table 1

Nutrient content of egg powder ( $\mathrm{g} / \mathrm{kg}$, as-fed basis) used in this experiment

\begin{tabular}{lr}
\hline ME (kcal/kg) & 3950 \\
Crude protein & 435 \\
Crude fat & 387 \\
Lysine & 69.9 \\
Methionine & 32.9 \\
Met+Cys & 57.0 \\
Threonine & 46.5 \\
Calcium & 0.50 \\
Available Phosphorus & 7.50
\end{tabular}

Immune organ size

At 7 and 42 days of age, four birds in each pen were individually weighed, slaughtered and eviscerated. Subsequently, internal organs include spleen and bursa were manually removed and individually weighed. Internal organ weights are presented as percent of body weight.

\section{Humoral immune responses}

Haemagglutination inhibition test against Newcastle disease virus: Newcastle disease virus (NDV) vaccine (killed vaccine, Formosa Biomedical Inc., Taipei, Taiwan) was administered at days 1 and 35 after hatching and peripheral blood was collected from the wing vein in the following week post-challenge each time. The titres of the antibody against Newcastle disease were determined by haemagglutination-inhibition test (Allan \& Gough 1974) and against infectious bursal disease by ELISA kit (IDEXX Laboratories Inc., Westbrook, ME, USA). 
Table 2

Composition and calculated nutrient content of diets fed in this experiment

\begin{tabular}{lcccccc}
\hline Feed Ingredients (g/kg) & \multicolumn{2}{c}{ Pre-starter $(0-7 \mathrm{~d})^{*}$} & \multicolumn{2}{c}{ Grower $(11-24 \mathrm{~d})$} & \multicolumn{2}{c}{ Finisher (25-42 d) } \\
& control & $20 \mathrm{~g} / \mathrm{kg}$ & $40 \mathrm{~g} / \mathrm{kg}$ & $60 \mathrm{~g} / \mathrm{kg}$ & & \\
\hline Corn & 515 & 525 & 534 & 543 & 587 & 591 \\
Egg powder & - & 20.0 & 40.0 & 60.0 & - & - \\
Corn Gluten Meal & 50.0 & 50.0 & 50.0 & 50.0 & 50.0 & 50.0 \\
Soybean Meal & 354 & 333 & 313 & 292 & 283 & 279 \\
Vegetable Oil & 31.9 & 24.7 & 18.0 & 11.3 & 36.7 & 42.0 \\
DL-Methionine & 2.46 & 1.94 & 1.50 & 1.06 & 1.80 & 1.10 \\
L-Lysine HCl & 3.04 & 2.23 & 1.42 & 0.61 & 2.60 & 1.00 \\
L-Threonine & 0.60 & - & - & - & 0.30 & - \\
Dicalcium Phosphate & 20.8 & 20.3 & 19.9 & 19.4 & 18.4 & 16.8 \\
CaCO3 & 13.0 & 13.3 & 13.7 & 14.1 & 10.8 & 10.5 \\
Na Bicarbonate & 1.60 & 1.20 & 0.70 & 0.30 & 1.40 & 0.70 \\
Common Salt & 2.30 & 2.60 & 2.90 & 3.10 & 2.50 & 3.00 \\
aVitamin and Mineral Premix & 5.00 & 5.00 & 5.00 & 5.00 & 5.00 & 5.00 \\
Nutrient content (g/kg, as-fed basis) & & & & & & \\
Crude Protein & 236 & 236 & 236 & 236 & 209 & 208 \\
ME (kcal/kg) & 3050 & 3050 & 3050 & 3050 & 3150 & 3200 \\
Lysine & 12.8 & 12.8 & 12.8 & 12.8 & 10.8 & 9.5 \\
Methionine & 5.90 & 5.80 & 5.80 & 5.80 & 5.00 & 4.20 \\
Met+Cys & 9.20 & 9.40 & 9.70 & 10.0 & 8.00 & 7.20 \\
Threonine & 8.10 & 8.10 & 8.70 & 9.30 & 6.90 & 6.50 \\
Calcium & 10.5 & 10.5 & 10.5 & 10.5 & 9.00 & 8.50 \\
Available Phosphorus & 5.00 & 5.00 & 5.00 & 5.00 & 4.50 & 4.20 \\
\hline
\end{tabular}

aPremix provided the following per kilogram of diet: $4.8 \mathrm{mg}$ of retinol acetate, $100 \mu \mathrm{g}$ of cholecalciferol, $20 \mathrm{mg}$ of DL-atocopheryl acetate, $4.5 \mathrm{mg}$ menadione sodium bisulphate, $4.1 \mathrm{mg}$ thiamine hydrochloride, $9.5 \mathrm{mg}$ of riboflavin, $15 \mathrm{mg}$ of calcium-D-pantothenate, $45 \mathrm{mg}$ of nicotinic acid, $9 \mathrm{mg}$ of pyridoxine hydrochloride, $2.2 \mathrm{mg}$ of folic acid, $0.25 \mathrm{mg}$ biotin, $12 \mathrm{mg}$ ascorbic acid, $550 \mathrm{mg}$ of choline chloride, $80 \mathrm{mg}$ of $\mathrm{Zn}, 30 \mathrm{mg}$ of Fe, $100 \mathrm{mg}$ of $\mathrm{Mn}, 20 \mathrm{mg}$ of Cu, $0.4 \mathrm{mg}$ of $\mathrm{Co}, 1.2 \mathrm{mg}$ of I, $0.4 \mathrm{mg}$ of Se. *All experimental groups after day 7 fed the same starter diet until day 10 of age as control group consumed from the beginning of the experiment.

Sheep red blood cell: at day 36 of age sheep red blood cell (SRBC) suspension ( $5 \% \mathrm{v} / \mathrm{v}$ in sterile PBS) was injected in breast muscle of four birds per treatment. Total antibody titres against SRBC were measured by agglutination according to Van der Zijpp \& Leenstra (1980) in the serum of the birds. Therefore, seven days after immunisation (day 42) antibody titres against SRBC were measured and expressed as the $\log _{2}$ of the reciprocal of the highest serum dilution giving complete agglutination.

Infectious bronchitis virus titre: Chickens were vaccinated against infectious bronchitis virus (IBV-Mass type, H120 strain, Merial Company) at the first day after hatching. Blood samples were collected by wing venipuncture at days 7 and 42 after hatching. The harvested sera were heat inactivated at $56^{\circ} \mathrm{C}$ for $30 \mathrm{~min}$. A commercial ELISA kit (Flockchek) from IDEXX Laboratories, Inc., Westbrook, Maine, USA, was used to determine IBV antibodies in sera of chickens, according to the manufacturer's instruction.

Infectious bursal diseases virus titre: Infectious bursal disease virus (IBD, Polymed, Tabic) vaccinations in drinking water were administered to 16 -day-old chickens. Blood samples were collected at days 7 and 42 of age to evaluate the IBD-ELISA antibody titres according the commercial kit manual (Biocheck ${ }^{\circledast}$ Inc., Foster City, CA, USA). 


\section{Cell mediated immune responses}

Contact sensitivity to 2,4 dinitro-1-chlorobenzene: Cell mediated immunity test was performed using 2,4 dinitro-1-chlorobenzene (DNCB) (Ajax Chemicals, Sydney, Australia). It was dissolved in a mixture of acetone and olive oil (4:1) (v/v) for each time of use. The test was performed as described by Chauhan \& Verma (1983). Briefly, at day 35 birds (four birds per replicate) were sensitised by painting DNCB, in $10 \mu \mathrm{l}$ of solvent, on a marked ring, $1 \mathrm{~cm}$ diameter, on the skin of the breast. To facilitate drying of the solvent, warm air was blown on the sensitising sites.

The response to DNCB was elicited a week after sensitisation by applying $50 \mu \mathrm{g}$ of DNCB, in $10 \mu \mathrm{l}$ of solvent, on the skin of the pelvic regions at day $42 ; 10 \mu \mathrm{l}$ of solvent were applied on the opposite side of the chickens to act as a negative control. Skin thickness at these two sites was measured with a micrometer after $24 \mathrm{~h}$ and differences stated as response to DNCB.

Injection of phytohaemagglutinin-P: The in vivo cell mediated immune response to phytohaemagglutinin-P (PHA-P) was studied at day 42 of age. The thickness of comb measured using micrometer (four birds per replicate). The comb was injected with $100 \mu \mathrm{g}$ of PHA-P (Sigma, St. Louis, MO, USA) suspended in $0.1 \mathrm{ml}$ of phosphate buffered saline. The comb swelling was measured after $24 \mathrm{~h}$ of injection. The cell mediated response was determined by subtracting the comb thickness of first measurement from the second (Corrier \& De Loach 1990).

\section{Statistical analysis}

Statistical analyses were conducted based on completely randomised design using the general linear model procedure of SAS for Windows version 9.1 (SAS Institute Inc., Cary, NC, USA) to determine whether variables differed between the groups. The KolmogorovSmirnov test was used to test the normal distribution of the data before statistical analysis was performed. The data were compared between the groups by Duncan multiple ranges test. Probability values of less than $0.05(P<0.05)$ were considered significant.

\section{Results}

\section{Internal organs}

As presented in Table 3, the application of egg powder in the pre-starter diet of male broilers affected the relative weight of immune related organs. According to these results increasing levels of egg powder in the pre-starter diet of birds reduced the relative weight of bursa at days 7 and 42 of age. Chickens which consumed the control diet had the highest bursal weight and the group of chickens consumed 40 and $60 \mathrm{~g} / \mathrm{kg}$ egg powder in their pre-starter diet had the lowest bursal weight at both ages $(P \leq 0.05)$. Spleen showed the same trend as bursa and increased level of egg powder inclusion in the pre-starter diet of broilers reduced the relative weight of spleen in both days 7 and 42 of age $(P \leq 0.05)$. There was not any difference between different levels of egg powder inclusion and only the control group differed from all experimental groups. 
Table 3

Effect of consuming different levels of egg powder in the pre-starter diet of male broiler chickens on relative weight (\%) of internal organs

\begin{tabular}{ccccccr}
\hline & & \multicolumn{5}{c}{ Level of egg powder inclusion in pre-starter diet } \\
& control & $20 \mathrm{~g} / \mathrm{kg}$ & $40 \mathrm{~g} / \mathrm{kg}$ & $60 \mathrm{~g} / \mathrm{kg}$ & SEM & $P$-value \\
\hline $\begin{array}{c}\text { Bursa } \\
7 \text { day }\end{array}$ & $0.25^{\mathrm{a}}$ & $0.23^{\mathrm{ab}}$ & $0.16^{\mathrm{b}}$ & $0.16^{\mathrm{b}}$ & 0.013 & 0.022 \\
$\begin{array}{c}\text { 4 day } \\
\text { Spleen }\end{array}$ & $0.19^{\mathrm{a}}$ & $0.17^{\mathrm{b}}$ & $0.14^{\mathrm{b}}$ & $0.14^{\mathrm{b}}$ & 0.008 & 0.019 \\
7 day & $0.10^{\mathrm{a}}$ & $0.08^{\mathrm{b}}$ & $0.07^{\mathrm{b}}$ & $0.07^{\mathrm{b}}$ & 0.004 & 0.004 \\
42 day & $0.13^{\mathrm{a}}$ & $0.09^{\mathrm{b}}$ & $0.09^{\mathrm{b}}$ & $0.08^{\mathrm{b}}$ & 0.005 & $<0.001$ \\
\hline
\end{tabular}

${ }^{\mathrm{ab}}$ Means in the same rows with different letter are significantly different $(P \leq 0.05)$

\section{Immune Parameters}

According to results presented in Table 4, most of the parameters related to the immune system were significantly affected by consuming egg powder in the pre-starter diet. Mean values presented for DNCB and SRBC test showed that by increasing the level of egg powder in the pre-starter diet, immunity response against DNCB and SRBC were increased but this increase was not significant $(P>0.05)$. The change in skin thickness response to DNCB in the control group was $1.32 \mathrm{~mm}$ and for birds consumed $60 \mathrm{~g} / \mathrm{kg}$ egg powders in their pre-starter diet it was $2.24 \mathrm{~mm}$. The same trend has been seen for the SRBC test.

Table 4

Effect of consuming different levels of egg powder in pre-starter diet of male broiler chicken on response of immune system to some stimulating factors.

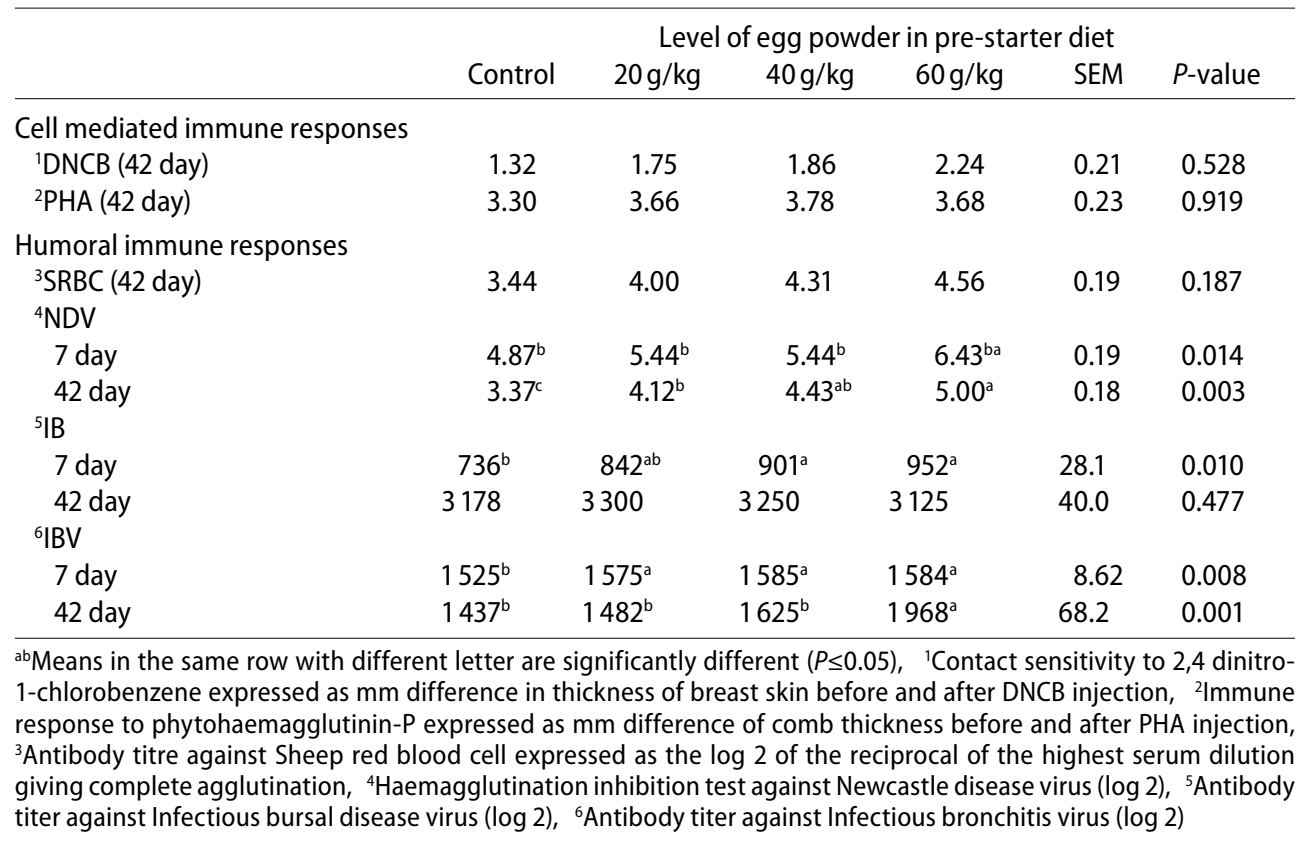


According to the mean values of haemagglutination inhibition titres of NDV presented in Table 4 , in both days 7 and 42 the haemagglutination inhibition test was affected by consuming egg powder in the pre-starter diet. An increase in the inclusion level of egg powder in the pre-starter diet of male broiler chickens significantly $(P \leq 0.05)$ enhanced antibody titres against NDV. Although the anti-NDV titre was reduced a little at 42 days of age in comparison to 7 days of age, differences between experimental treatments were clearer at 42 days of age.

The immune system response to PHA injection in the comb of chickens was measured as an increase in the thickness of the comb. Although there was a little difference between control and experimental treatments in case of response to PHA injection, the differences were not significant $(P>0.05)$ and there was almost no difference between chickens consumed diets with different levels of egg powder.

The antibody titre against IBDV was measured in days 7 and 42 . The level of the antibody titre in the serum of male broiler chicken was affected by the level of egg powder in their prestarter diet. Although the IBD vaccine was administered at day 16 after hatching, the antibody titre at day 7 of age was measured to determine the level of the antibody in maternal flock. At day 7 , the antibody titre against IBD was significantly affected by consuming egg powder in the pre-starter diet. Chickens consumed egg powder in their pre-starter diet had higher levels of the antibody titre against IBD in comparison with the control group. The antibody titre against IBD at day 42 was higher than at day 7 because of the vaccination against IBD administered at day 16 after hatching. Although the level of antibody was higher at day 42 , there was no significant difference between the antibody titre of chickens consumed control or experimental diets $(P>0.05)$.

Additionally, the antibody titre against IBV was measured in the experiment. The infectious bronchitis vaccine was administered at the first day after hatching. Results presented in Table 4 showed that at days 7 and 42 of age, the antibody titre was affected by consuming egg powder in the pre-starter diet $(P \leq 0.05)$. At day 7 of the experiment all chickens consumed egg powder in their pre-starter diet had higher levels of anti-IBV in comparison with the control group. At day 42 of the experiment only birds consumed $60 \mathrm{~g} / \mathrm{kg}$ egg powder in the pre-starter diet significantly $(P \leq 0.05)$ had higher levels of the antibody titre and other experimental groups had no difference with control group.

\section{Discussion}

Because bursa and spleen have direct relations to the immune system, with regard to results presented in Table 3, the application of egg powder in the pre-starter diet of male broiler chickens significantly reduced the relative weight of these organs at days 7 and 42 of age. According to different studies carried out on nutritional values and positive effects of egg on immune system, the reduction in relative weight of organs related to the immune system could be explained. Egg is rich in fat, high quality protein, maternal antibody and bioactive nutrients (Schaafsma et al. 2000, Anton et al. 2006, Sparks 2006). In a study carried out by Burley \& Vadehra (1989) positive effects of egg components on the immune system by inhibition of haemagglutination by viruses were also stated. Because egg powder was highly digestible, birds could consume egg powder efficiently. Growth and development of gastrointestinal tract and immune system of these birds occurred in a good manner and so 
the health of birds was warranted and challenges like antigens did not affect the immune system of chickens.

Results presented in Table 4 showed that many of the immune system responses enhanced due to feeding egg powder in the pre-starter diet. The effect of consuming egg powder in the pre-starter diet on the immune system responses was very sharp and clear. Looking for a good reason to explain these effects leads us to the nutritional value of eggs for chickens prior to the hatching period. An egg during the incubation period provides all nutritional requirements of the chicken embryo and there is a very strong relation between egg weight and subsequent hatched chicken weight. According to some studies (Sulistiyanto et al. 1999, Sklan et al. 2000) regardless of the type of feed, the presence of feed in early times after hatching had a great effect on health and production of chickens. Firstly, by the presence of feed birds could consume the antibodies absorbed in the yolk sac to improve their immune system and protect themselves against undesirable antigens. Secondly, the presence of feed helps the chickens to provide essential nutrients to speed up the growth of internal organs, especially of the digestive tract, to support the final growth and production of the bird (Noy \& Sklan 1999).

The most important point after the immediate access to feed is the nutritional value of feed ingredient for chickens in early time after hatching. The importance of early feeding of newly hatched chicks on their performance and health was adequately demonstrated by several studies (Jin et al. 1998, Noy \& Sklan 1999, Juul-Madsen et al. 2004). Most of the feed ingredients like grains and plant origin proteins that are used in the diet of chickens had a low utilisation for chickens in early times after hatching. The main reason of this poor ability is the immature gastrointestinal tract of chickens (Juul-Madsen et al. 2004). In addition to that disability, newly hatched chickens have a high level of nutrient requirements because of their accelerated growth of the gastrointestinal system and other organs related to nutrition and immunity.

Many studies documented the nutritional value of eggs and egg products. Eggs are known to be rich in fat, maternal antibodies, protein, bioactive nutrients and lysozyme (Schaafsma et al. 2000, Anton et al. 2006, Sparks 2006). Positive effects of egg components on the immune system and the inhibition of haemagglutination by viruses are also showed in a study by Burley \& Vadehra (1989).

Eggs contain antibodies against all challenges to which hens has been exposed and this is attractive since they do not cause inflammatory responses they can provide protection against enteric infections (Burley \& Vadehra 1989, Davis \& Reeves 2002). Also egg yolk is a reservoir of antibodies with many proven uses and applications (Li-Chan 1998, Anton et al. 2006, Sparks 2006).

With regard to the facts and discussions presented above, all positive effects of consuming egg powder in the pre-starter diet of chickens and all results obtained in this study could be explained. Egg powder was an ingredient with high levels of utilisation for chickens in the early times after hatching. High levels of digestibility and utilisation of egg powder relieved the incapability of the gastrointestinal system of newly hatched chickens. Growth and development of the gastrointestinal system and of other organs of young chicken could be warranted by supplying required nutrients.. 


\section{References}

Allan WH, Gough RE (1974) A standard haemagglutination inhibition test for Newcastle disease. (1). A comparison of macro and micro methods. Vet Rec 95, 120-123

Anton M, Nau F, Nys Y (2006) Bioactive egg components and their potential uses. Worlds Poult Sci J 62, 429-438

AOAC (1990) Official Methods of Analysis, 15th ed., Association of Official Analytical Chemists, Washington, USA, 281-292

Burley RW, Vadehra DV (1989) The Avian Egg: Chemistry and Biology. Wiley, New York, USA, 167-173

Chauhan HVS, Verma KC (1983) Evaluation of cell mediated immunity of Marek's disease. British Vet J 139, 57-65

Corrier DE, DeLoach JR (1990) Evaluation of Cell-Mediated Cutaneous Basophil Hypersensitivity in Young Chickens by an Interdigital Skin Test. Poult Sci 69, 403-408

Davis C, Reeves R (2002) High value opportunities from the chicken egg. A report for the Rural Industries Research and Development Corporation. RIRDC Publication, Barton, Australia

El-Deek AA, Al-Harthi MA (2009) Effect of Dried Whole Eggs Processed by Various Ways on Pullet's Performance and Egg Production and Quality Traits. Int J Poult Sci 8, 1086-1092

El-Deek AA, Al-Harthi MA, Attia YA (2011) Effect of different dietary levels of dried eggs by-product without or with shell on the performance of laying strain chicks from 2 to 8 wk of age. Arch Geflügelk 75, 20-29

Jin SH, Corless A, Sell LJ (1998) Digestive system development in post-hatch poultry. Worlds Poult Sci J 54, 335-345

Juul-Madsen HR, Su G, Sørensen P (2004) Influence of early or late start of first feeding on growth and immune phenotype of broilers. Br Poult Sci 45, 210-222

Kirk CK (1997) Interaction between nutrition and infections disease Infectious disease. In: Calnek BW (ed.) Diseases of poultry, 10th ed., Mosby-Wolfe, London, UK, 73-74

Li-Chan ECY (1998) Applications of egg Immunoglobulins in immunoaffinity chromatography and immunoassays-separation technology, research and industrial applications. In: Second International Symposium on Egg Nutrition and Newly Emerging Ovo-Biotechnologies. Banff, AB, Canada, 32

Noy Y, Sklan D (1999) Different Types of Early Feeding and Performance In Chicks and Poults. J Appl Poult Res $8,16-24$

Noy Y, Sklan D (2001) Yolk and exogenous feed utilization in the posthatch chick. Poult Sci 80, 1490-1495

ROSS (2009) Broiler management manual, Aviagen Limited, Newbridge, Midlothian EH28 8SZ, Scotland, UK

SAS (2001) SAS/STAT User's Guide: Version 9.1., SAS Institute Inc., Cary, NC, USA

Schaafsma A, Pakan I, Hofstede GJH, Muskiet FAJ, Van Der Veer E, De Vries PJF (2000) Mineral, Amino Acid and Hormonal Composition of Chicken Eggshell Powder and the Evaluation of its Use in Human Nutrition. Poult Sci 79, 1833-1838

Sklan D, Noy Y, Hoyzman A, Rozenboim I (2000) Decreasing Weight Loss in the Hatchery by Feeding Chicks and Poults in Hatching Trays. J Appl Poult Res 9, 142-148

Sparks NHC (2006) The hen's egg - is its role in human nutrition changing? World's Poult Sci J 62, 308-315

Sulistiyanto B, Akiba Y, Sato K (1999) Energy utilisation of carbohydrate, fat and protein sources in newly hatched broiler chicks. Br Poult Sci 40, 653-659

Van der Zijpp AJ, Leenstra FR (1980) Genetic Analysis of the Humoral Immune Response of White Leghorn Chicks. Poult Sci 59, 1363-1369 